Article

\title{
Ecosystem Services Assessment Tools for Regenerative Urban Design in Oceania
}

\author{
Fabian Delpy ${ }^{1}$, Maibritt Pedersen Zari ${ }^{2, * \mathbb{D}}$, Bethanna Jackson ${ }^{3}$, Rubianca Benavidez ${ }^{3}$ (D) and Thomas Westend ${ }^{2}$ \\ 1 Department of Biology, Utrecht University, Padualaan 8, 3584 CH Utrecht, The Netherlands; \\ f.p.delpy@students.uu.nl \\ 2 Wellington School of Architecture, Victoria University of Wellington, 139 Vivian Street, Wellington 6011, \\ Aotearoa, New Zealand; thomas.m.westend@gmail.com \\ 3 School of Geography, Environmental and Earth Science, Victoria University of Wellington, Kelburn Parade, \\ Wellington 6012, Aotearoa, New Zealand; bethanna.jackson@vuw.ac.nz (B.J.); \\ rubianca.benavidez@vuw.ac.nz (R.B.) \\ * Correspondence: maibritt.pedersen@vuw.ac.nz
}

Citation: Delpy, F.; Pedersen Zari, M.; Jackson, B.; Benavidez, R.; Westend, T. Ecosystem Services Assessment Tools for Regenerative Urban Design in Oceania. Sustainability 2021, 13, 2825. https://doi.org/10.3390/su13052825

Academic Editor: Jianguo Wu

Received: 16 December 2020

Accepted: 26 February 2021

Published: 5 March 2021

Publisher's Note: MDPI stays neutral with regard to jurisdictional claims in published maps and institutional affiliations.

Copyright: (c) 2021 by the authors. Licensee MDPI, Basel, Switzerland. This article is an open access article distributed under the terms and conditions of the Creative Commons Attribution (CC BY) license (https:// creativecommons.org/licenses/by/ $4.0 /)$

\begin{abstract}
Tools that spatially model ecosystem services offer opportunities to integrate ecology into regenerative urban design. However, few of these tools are designed for assessing ecosystem services in cities, meaning their application by designers is potentially limited. This research reviews and compares a range of ecosystem services assessment tools to find those that are most suited for the urban context of Oceania. The tool classification includes considerations of type of input and output data, time commitment, and necessary skills required. The strengths and limitations of the most relevant tools are further discussed alongside illustrative case studies, some collected from literature and one conducted as part of this research in Wellington, Aotearoa using the Land Utilisation and Capability Indicator (LUCI) tool. A major finding of the research is that from the 95 tools reviewed, only four are judged to be potentially relevant for urban design projects. These are modelling tools that allow spatially explicit visualisation of biophysical quantification of ecosystem services. The ecosystem services assessed vary among tools and the outputs' reliability is often highly influenced by the user's technical expertise. The provided recommendations support urban designers and architects to choose the tool that best suits their regenerative design project requirements.
\end{abstract}

Keywords: ecosystem-based adaptation; multidisciplinary design; urban ecology; Pacific islands; nature-based design; SIDS; climate change adaptation; New Zealand; urban design

\section{Introduction}

The typical path of the development of human civilisation has degraded ecosystems, caused climate change, and led to biodiversity loss [1,2]. The design, construction and use of urban built environments has greatly contributed to these issues [3]. This fact, combined with the knowledge that more than half of all humans now live in urban areas, means that the re-conceptualisation and adaptation of urban areas must be part of a suite of responses to climate change and biodiversity loss [4]. To face these challenges in a context of rapid global urbanisation, cities must develop both adaptation and mitigation strategies that create societal health while concurrently regenerating the functions of degraded ecosystems, reducing or eliminating greenhouse gas emissions, and restoring biodiversity [5]. Current and future environmental pressures include increased extreme precipitation events, droughts, flooding [6], urban heat stress [7], poor air quality [8], and for coastal settlements in particular, sea level rise [9]. Climate adaptation and mitigation strategies must create societal and ecological health, regenerating the functions from degraded ecosystems and preserving biodiversity. This implies a need to move away from conventional urban and architectural design paradigms and towards nature inclusive practices and regenerative design $[10,11]$. 


\subsection{Ecosystem-Based Adaptation}

Nature-based Solutions (NbS) work with, conserve, and restore nature in order to both increase human well-being and provide ecological benefits [12]. NbS is an umbrella term for several more specific concepts that aim to work with nature to improve the built environment, human health, and ecological functioning, by understanding relationships between the drivers and impacts of change [13]. Ecosystem-based adaptation (EbA) is an aspect of $\mathrm{NbS}$ and is gaining recognition and momentum among designers of the built environment in line with this new paradigm. EbA draws upon knowledge of ecosystem services to increase ecosystems' and communities' resilience to the impacts of climate change through development strategies that strengthen biodiversity and ecosystems [14] (Figure 1). Ecosystem services represent the benefits human populations derive, directly or indirectly from ecosystems [15]. Ecosystem services have been described and organised in several different ways and were popularised as a concept by the Millennium Ecosystem Services Assessment series of reports in 2005 [16]. Typical examples of ecosystem services include provisioning ecosystem services such as the provision of food and the provision of fresh water; regulating ecosystem services such as climate regulation, pollination, purification of air, water, and soil; supporting ecosystem services such as nutrient cycling and habitat provision; and cultural ecosystem services such as recreation, relaxation, and education $[10,17]$. The authors, among many others, consider that it is important to highlight that when shifting towards nature inclusive design practices, ecosystem services frameworks should be considered with a biocentric lens, where the question "how can ecosystems serve humans?" is paired with "how can humans contribute to the health of ecosystems and live symbiotically as part of them?" [18].

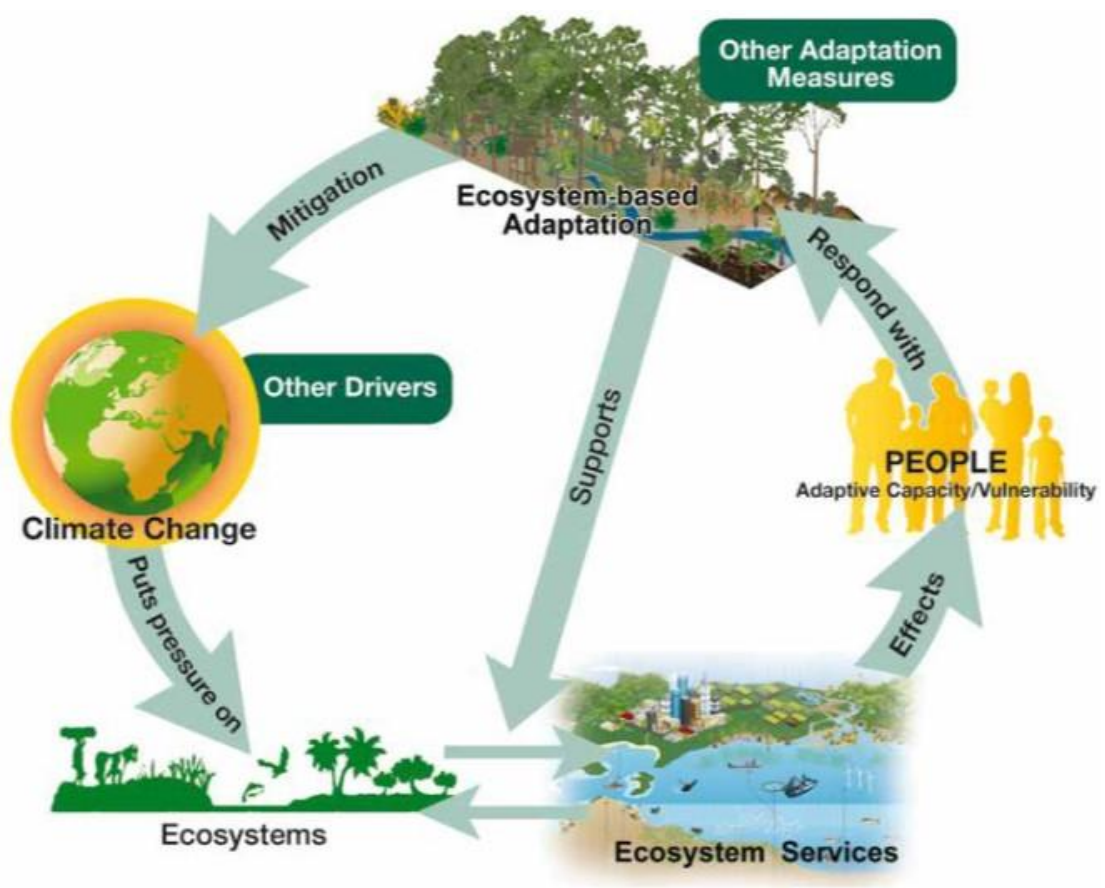

Figure 1. Ecosystem-based adaptation framework (source: Andrade Pérez, A., et al., 2010).

\subsection{Regenerative Urban Design}

Regenerative design is a holistic systems-based approach to built environment design that centers on increasing the wellbeing of human individuals, communities, and wider living systems through various methods [19]. One aspect of regenerative design is addressing the degradation of biological ecosystems by designing and developing the built environment in such a way that it restores the capacity of ecosystems to function at optimal health for the benefit of human and non-human life alike [10]. 
A framework and process for integrating ecosystem services into regenerative urban design has been proposed by Pedersen Zari [10]. This framework specifically investigates how cities could emulate the functions of ecosystems and suggests that the ecological performance goals of a design should be based on levels of ecosystem services provision found on the same site before the existence of the city, and thus based on the ecological and climatic reality of a site. The proposed four step "urban ecosystem services analysis" process begins with a comparison between past ecosystem services provision determined by examining the native ecosystem that would have existed on the site of the city prior to urban settlement and present ecosystem services provision in the existing city. In order to make this comparison, an assessment of ecosystem services provision must be conducted, much as EbA design processes often begin with an assessment of existing ecosystem services provision [20].

It is clear from both regenerative urban design and $\mathrm{EbA}$ processes that designers should integrate ecosystem services assessment early in the design process in order to re-design or create urban areas that regenerate the functions of ecosystems to work towards a human symbiosis with the rest of the living world.

\subsection{Oceania and Ocean Cities}

This research focuses on "Ocean Cities" in Oceania, defined here as urban settlements of the islands of Micronesia, Melanesia, and Polynesia, including Aotearoa New Zealand, together with the vast ocean areas between those islands (Figure 2). Ocean Cities are ones "where urban landscapes and seascapes meet, where built and natural environments near coastlines interface, and where human behavior and urban development have profound impacts on both terrestrial and marine ecosystems" [5] (p. 6).

Ocean Cities are confronted by specific challenges in the face of climate change and therefore require tailored adaptation strategies and practices to ensure resilience against coastal flooding and erosion, increasing droughts, and extreme rainfall events [21]. Moreover, these future developments must account for Ocean City characteristics such as unique cultural contexts; relatively small populations; and limited usable land area, natural resources, adaptation capacity, and development options [22]. Aotearoa New Zealand has undergone different urban and infrastructure development as compared to most other island nations of Oceania because of historical and cultural differences, larger land area and population, and higher per capita income. The country faces however, similar ecological and climatic challenges related to a highly urbanised and coastal population; high rates of endemism as well as high rates of biodiversity loss; and climate change induced sea level rise, storm surge, changes in precipitation, and changes in storm patterns and intensities [23].

The city of Wellington is strategically densifying to cope with population increase [24]. Wellington City Council has developed the vision of a "compact, liveable city" and aims to provide additional green infrastructures that ensure the health of its citizens and resilience against future environmental change [25].

The islands of the Pacific, with their unique land and marine ecologies, are at the frontline of climate change impacts and are emerging as leaders in the area of nature-based solutions and EbA specifically [5]. This may in part be because nature-based solutions are thought to potentially offer more culturally appropriate approaches to climate change adaptation [26]. EbA projects could greatly benefit from tools that model ecosystem services, as illustrated by a recent project in Port Vila, Vanuatu [20], and supported by research highlighting the need to develop approaches for ecosystem services assessment that make use of empirical and spatial data for island ecosystem management [27]. In the Port Vila project, funded by the Pacific Ecosystem-Based Adaptation to Climate Change (PEBACC) programme and implemented by the Secretariat of the Pacific Regional Environment Programme (SPREP), researchers devised a methodology for developing urban EbA projects in a small island developing nation (SIDS) context that included the use of an ecosystem assessment tool. Much like the process of regenerative design proposed by Pedersen 
Zari [10], it was found that to successfully conceive of EbA projects, it is necessary to conduct biophysical assessments of ecosystem services on site as an aid to decision making, communication, and elaboration of locally attuned adaption development strategies [28]. The question remains, how can designers conduct these ecosystem services assessments, particularly in the unique context of Oceania? The remainder of this article details a number of tools that have potential to be used to support ecosystem services assessments in the context of Ocean Cities.

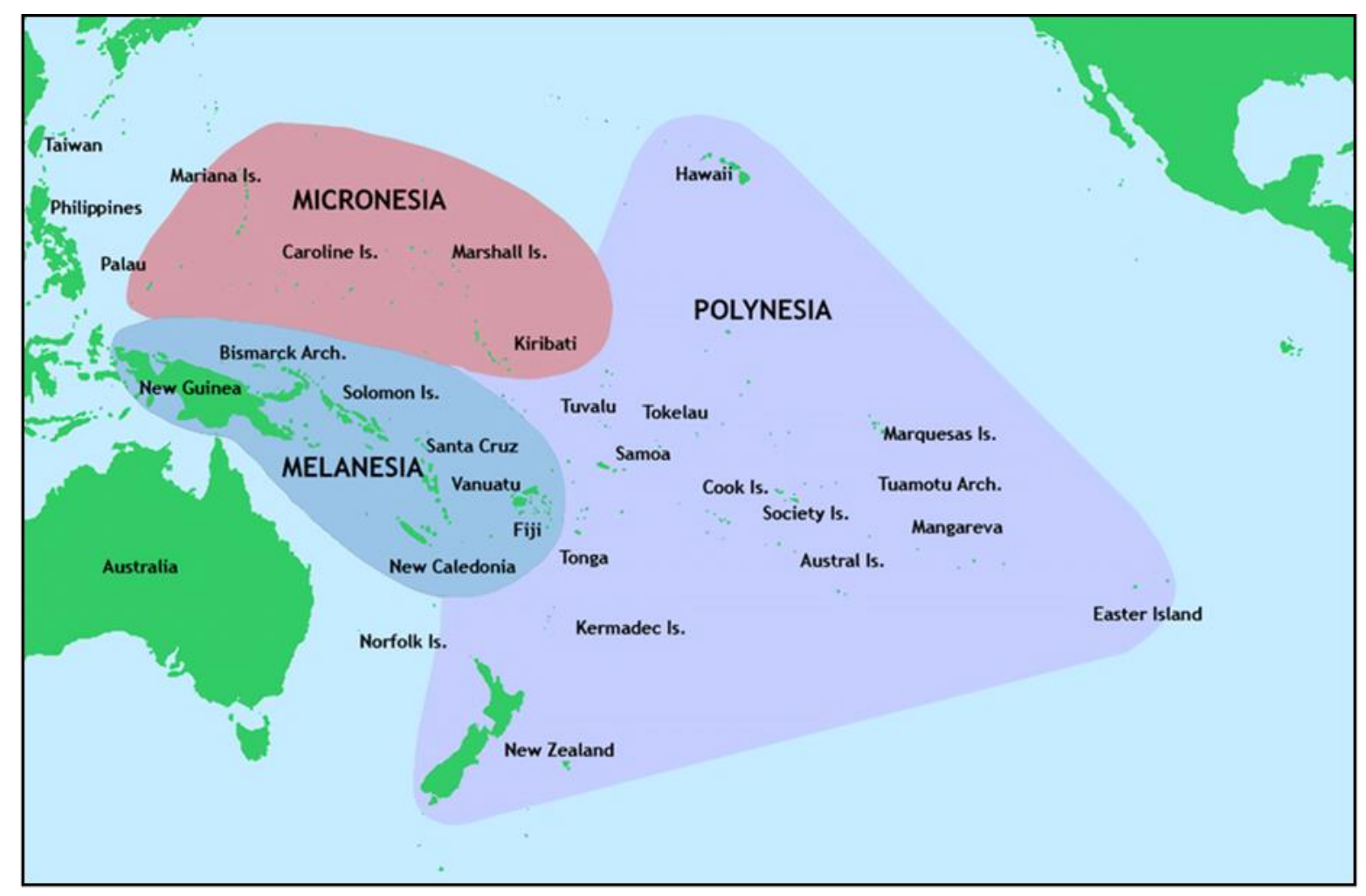

Figure 2. Nations of Oceania.

\subsection{Ecosystem Services Tools}

There is a wide range of tools that identify, characterise, quantify and value ecosystem services [29]. These tools include field surveys, interviews, public participation, remote sensing, and GIS mapping. Some focus on biophysical quantification of ecosystem services while others assess social benefits or monetary value. They are applied in different contexts such as nature conservation and restoration planning, policy making, environmental impact assessment, and participatory planning with local communities. These tools are available to designers of the built environment and some have the potential to be applied for $\mathrm{EbA}$ and nature-based and/or regenerative design in an urban context. Enabling designers of the built environment to access and apply ecosystem services assessment tools can facilitate the inclusion of ecological values early in the design process. However, the variety and complexity of the tools available may be confusing for designers without a basic working knowledge of ecology. Indeed, very diverse decision-support tools for ecosystem services quantification and valuation are reported in the literature [30]. Some tools have been developed in various countries to be specifically adapted to the local context and as such are not always transferable to new geographical and cultural contexts. Moreover, the number and type of ecosystem services that each tool considers, the expertise required, the affordability, and the scalability vary greatly.

This research reviews ecosystem services assessment tools and evaluates them for their applicability to urban sites in Oceania. It does not aim to detail every tool; other publications exist that do this already (e.g., [30-32]). Instead, the research aims to assess 
the technical strengths and limitations of each tools for practical application, particularly by design teams. The results are presented in a form that guides urban design teams to choose the tools that best suit their project requirements and level of expertise. Focus on the use of ecosystem services tools as a component of regenerative design and $\mathrm{EbA}$ is this research's contribution to knowledge. The tools' evaluation is illustrated with case studies and complemented by a pilot study of one tool (Land Utilisation and Capability Indicator (LUCI)) in the urban context of Wellington, Aotearoa New Zealand.

\section{Methods}

The systematic identification and evaluation of ecosystem services tools that are suitable for urban designers and architects in Oceania consisted of four main steps. This methodological approach was largely informed by recent research from Hugé et al. who elaborated similar user-informed classification of ecosystem services tools in the context of African Biosphere Reserves [33].

Firstly, an extensive list of ecosystem services assessment tools, frameworks, guidelines, and methods (collectively referred to as "tools") was drawn up. Secondly, the list was shortened by selecting only the tools that fit certain criteria (Table 1). Thirdly, the list was further narrowed based on designers' needs and requirements to carry out ecosystem services assessment in an urban context in Oceania. Lastly, the selected tools were classified and evaluated based on available case studies in the Oceania context. In addition to the case studies analysed through literature review, one of the tools identified as being suitable for further consideration, LUCI, was applied in the urban context of Wellington, Aotearoa New Zealand. Details of each step are elaborated on below.

\subsection{Step 1: Screening of Ecosystem Services Tools in the Literature}

Hugé et al. [33] came up with a list of 87 tools after reviewing specialised scientific journals and databases using different scientific search engines. To check and to complement the list from Hugé et al. [33], an investigation was made through ecosystem services related databases, tool official websites, and the scientific search engine Google Scholar. Considering that Bagstad et al. [30] already reviewed the most important tools up until 2013, the research on Google Scholar filtered publications from 2014 onward using the following entry: "Ecosystem services assessment" OR "Ecosystem services valuation" OR "Ecosystem services mapping" AND Urban OR City. 2.2 Step 2: Exclusion of Irrelevant Tools.

The list was then shortened based on an initial set of criteria used by Hugé et al. in their first screening (Table 1). The tools that satisfied these conditions were then described in detail to enable further evaluation based on user requirements. Information for this evaluation process was obtained through different lines of investigation using a triangulation approach. Investigation methods included searching on the scientific research engine Google Scholar with the entry "name of the tool" (e.g., "InVEST" or "Integrated Valuation of Ecosystem Services and Tradeoffs") from 2014 onward; review of every article referencing the original developer's publication of the tool; and examination of the tool's official website. The key sources for this step included [21,31-35]. It is beyond the scope of this article to publish these initial detailed results, but spreadsheets are available from the authors if required.

\subsection{Step 3: Selection of Tools Suitable for Urban Context}

The list of tools was then refined a second time with a set of criteria that relates to designers' needs and requirements (Table 2). Urban designers' and architects' specific needs and requirements were elaborated upon based on a series of one-on-one in-depth semi-structured interviews with four senior academic specialists in the field of ecosystem services urban design at the School of Architecture, Victoria University of Wellington, and were further complimented by feedback received from two urban designers during a 
collaborative pilot study (see Section 2.4). This step was inspired from Hugé et al., who also inquired about users' preferences, but the criteria were adapted to fit an urban context.

Table 1. Initial set of criteria for tool evaluation.

\begin{tabular}{|c|c|}
\hline Criteria & Type of Tools Excluded \\
\hline Ready to use & Prototypes, tools under development, or those not available anymore \\
\hline Generalisable & $\begin{array}{l}\text { Tools that are not applicable across a variety of social-ecological } \\
\text { settings and tools that are restricted to specific application in a single } \\
\text { sector (e.g., agriculture, planning for policy) }\end{array}$ \\
\hline Availability & Proprietary tools \\
\hline Reviewed in literature & Tools with very limited information available to public \\
\hline $\begin{array}{l}\text { Consider multiple } \\
\text { ecosystem services }\end{array}$ & Tools that only consider/examine only a single ecosystem \\
\hline
\end{tabular}

Table 2. Second set of criteria based on urban designers needs and requirements.

\begin{tabular}{ll}
\hline \multicolumn{1}{c}{ Criteria } & \multicolumn{1}{c}{ Type of Tools Excluded } \\
\hline $\begin{array}{l}\text { Preference for small } \\
\text { scale and good } \\
\text { resolution }\end{array}$ & Tool limited to scale larger than regional \\
$\begin{array}{l}\text { Biophysical assessment } \\
\text { Spatially explicit outputs } \\
\text { Easy to interpret outputs }\end{array}$ & $\begin{array}{l}\text { Tools that do not provide biophysical assessment of ecosystem } \\
\text { services. Monetary and social value are secondary outputs } \\
\text { Tools that do not provide spatially explicit outputs } \\
\text { Applicable }\end{array}$ \\
$\begin{array}{l}\text { Tools that only provide absolute values without further information } \\
\text { Tools that require skill typically beyond urban designer and architect } \\
\text { expertise. GIS-related skills are acceptable, whereas economic } \\
\text { expertise is not for example } \\
\text { Tools that require large financial investment. This did not exclude } \\
\text { sffordability }\end{array}$ & software such as ArcGIS which is commonly accessible to designers \\
\hline
\end{tabular}

\subsection{Step 4: Tools Classification and Evaluation}

The tools satisfying the second set of criteria were then further evaluated based on case studies. The initial literature research on Google Scholar was complemented with additional cases studies obtained on the tools' official websites, ecosystem servicesrelated databases, and using the Google Scholar engine research with the following entries: "ecosystem services assessment" OR "ecosystem services valuation" OR "ecosystem services mapping" AND “Oceania" OR "Pacific" OR "SIDS" OR "small island developing states" OR the names of each nation in Oceania. The research context for the case studies analysis was extended to cope with the lack of tool application in Oceania. The geographical boundaries were adapted to consider islands or coastal environments in Asia and the Caribbean along with some continental locations when judged relevant. This is because geographical and climatic similarities with other parts of the world require similar tool functionality.

\subsection{LUCI Application in Wellington, Aotearoa New Zealand}

To complement the theoretical information from the literature review with practical detail, one of the reviewed tools, LUCI, was applied at two different scales in the urban context of Wellington, Aotearoa New Zealand. LUCI was chosen for this research because it was easily accessible by the researcher, who had to opportunity to meet the developers in person, allowing for in-depth discussion on LUCI's existing tools and potential for supporting sustainable urban design planning. The tool met the selection criteria and had already been used in New Zealand and wider Oceania. Further details of why LUCI was chosen are given in Section 3.4.

The study site at the larger urban scale is Wellington city centre which includes a surrounding green belt. Boundary lines were based on local census area units in the builtup part of the city near the harbor edge and extend back to include larger areas of the 
watershed to the west. Wellington is a complex folded geography of hills and valleys with a flat central business district (CBD). The CBD, located on the edge of the harbor, is a dense urban settlement of high rise and medium density commercial and residential premises. It is surrounded by a green belt of urban parklands and forest [24]. The surface area of the site is approximately $37.4 \mathrm{~km}^{2}$ and is comprised of several streams flowing from the hills down to the sea, many of which are culverted beneath the city. The highest of the hills encircling the CBD, Brooklyn hill, rises $299 \mathrm{~m}$ above sea level. The Terrace Gardens site is a residential/commercial area within the larger Wellington city centre site (Figure 3). Within the site, there are private residential properties surrounded by vegetation and two public green spaces: Terrace Gardens, and Flagstaff Hill, owned by the Wellington City Council [24]. These are maintained as recreational urban park areas [36]. The site surface area is approximately $16378 \mathrm{~m}^{2}\left(0.016 \mathrm{~km}^{2}\right)$. The slope gradient varies between 20 and $40 \%$. The two recreational areas are covered with grass and the rest of the site is made up of a mixture of mostly native species of various ages along with exotic deciduous vegetation, including shrubs and trees. The Terrace Gardens location was chosen in this pilot study because previous research recently assessed ecosystem services on the same site using the Ecosystem Services Identification and Inventory (ESII) tool [37].

The LUCI analyses were conducted at both site scales following the tool's documentation and guidelines which were received during communication with the developers [38]. The LUCI tool workflow consists of six parts (Figure 4). This project only explored steps one to four, however, because it was a pilot analysis to evaluate the usability of LUCI at different scales.

LUCI requires three essential data inputs: a digital elevation model (DEM), land cover information, and soil information. The stream network, rain annual average, and annual average evaporation information are optional data that were added to enhance the output's quality and robustness [39]. A description of the input data used in this project is presented in Table 3 which are all national and regional datasets already supported by LUCI.

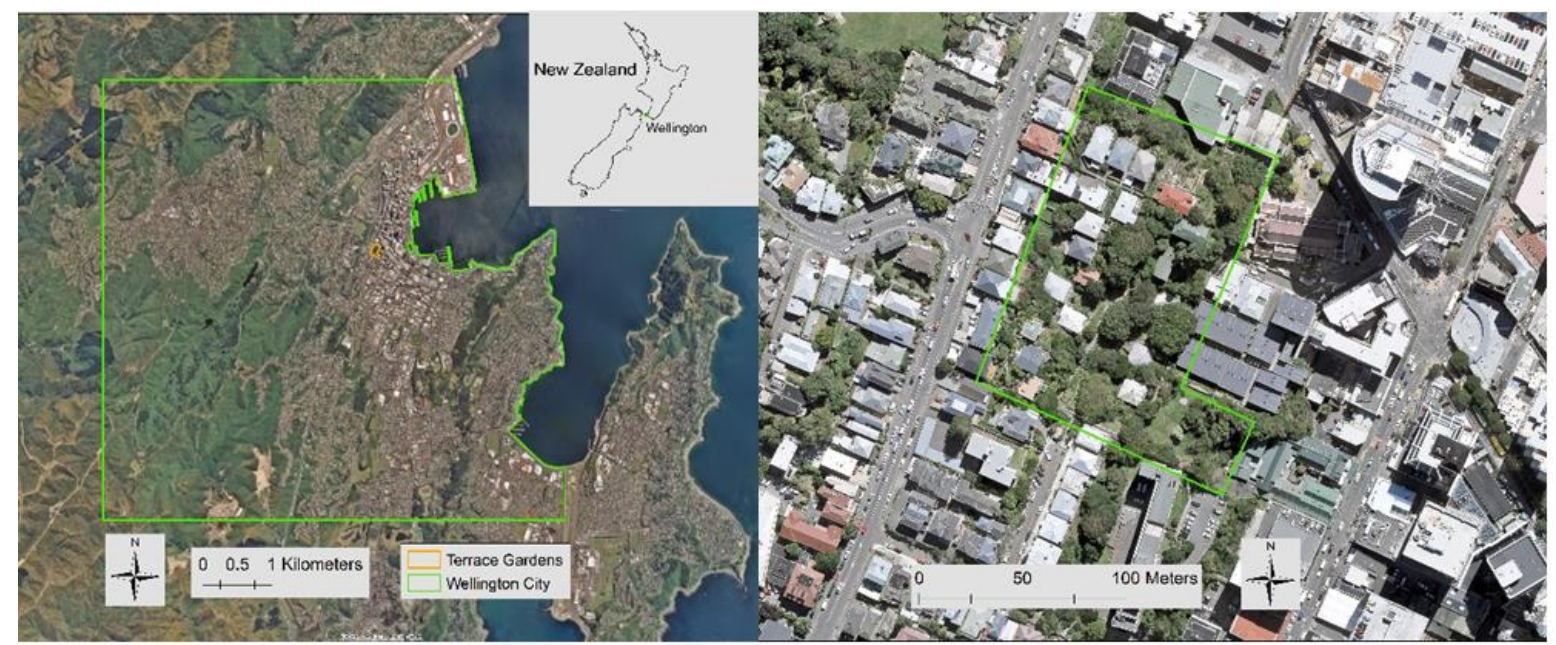

Figure 3. Pilot study sites (left: Central Wellington; right: Terrace Gardens). 


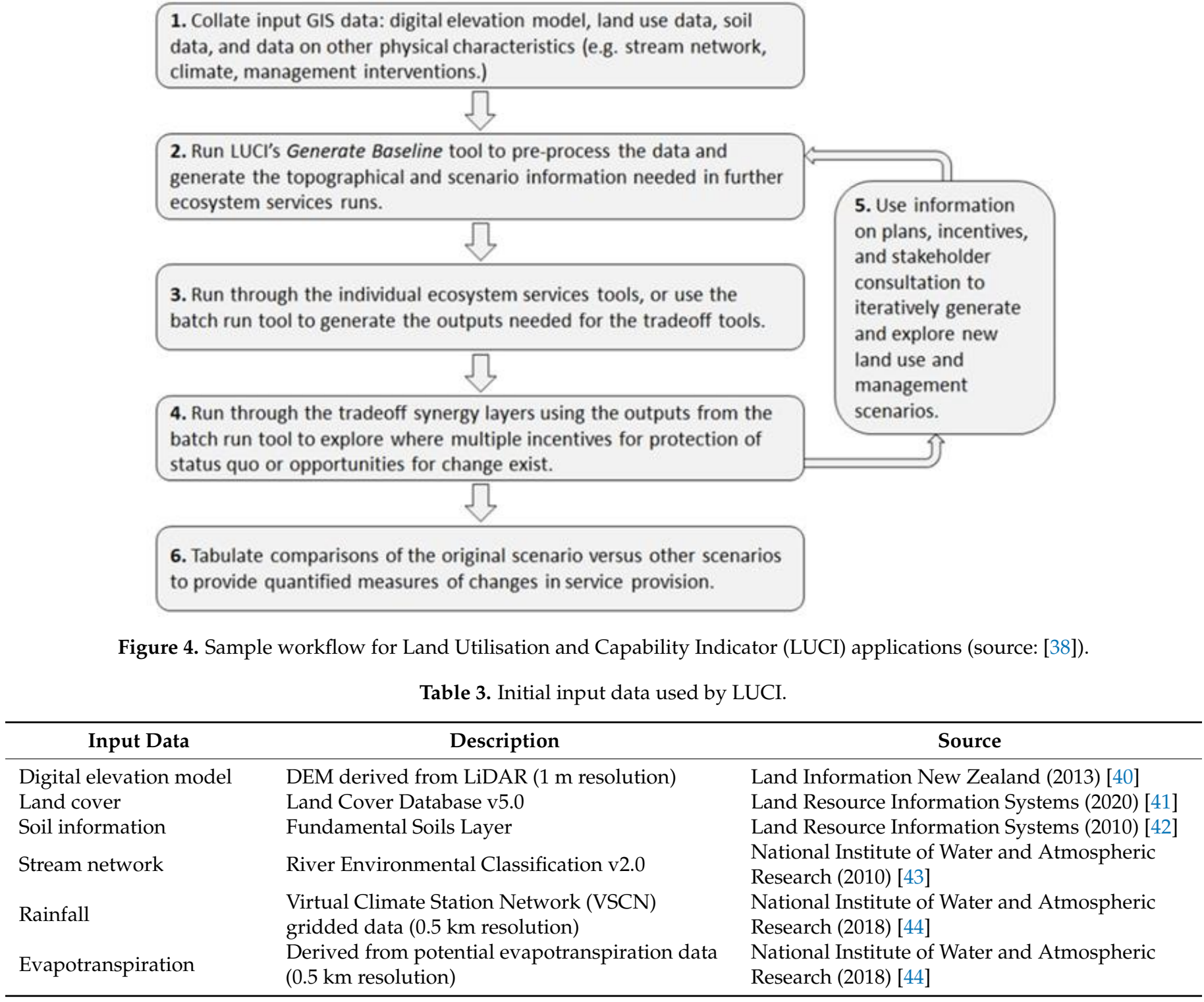

The initial set of input data was pre-processed with the LUCI's Generate Baseline tool. On the Terrace Gardens site, the stream network dataset was replaced by the automated model of LUCI that generates the river network directly from the DEM. This was necessary because there were not any streams flowing on the site. The outputs generated by the baseline tool were then run through the individual LUCI ecosystem services tools on both study sites. LUCI is comprised of nine models: agricultural productivity, carbon stocks and fluxes, erosion and sediment, flood mitigation, habitat connectivity, habitat suitability, nitrogen, phosphorus, and soil loss (RUSLE). The two habitat-related models were not run in this project because they were mainly parameterised for UK broadleaved woodland species and not yet for New Zealand (NZ) species (although there is ongoing work within LUCI to parameterise for NZ native species). The tools were run with the default input setting except the RUSLE tool for which specific Wellington region inputs were obtained from Klik et al. [39].

The outputs from the individual ecosystem services tools were then used to run the LUCI trade-off and synergy tool. Different ecosystem services combinations were tested, including two to six ecosystem services combinations per analysis. The RUSLE model was not available for use with the trade-off tool because it was developed later. The national land cover data (LCDB4/5) are what is freely available and commonly used around NZ for 
land cover inputs including LUCI, but the national land cover data do not always capture site-specific information such as small green areas that the land cover dataset represents as just "urban". This indicates that field work is important in order to further delineate different land cover types that the national data do not pick up on. In light of this, field analysis at the Terrace Gardens site was undertaken and the relative generated outputs were compared to the initial analysis based on national land use input data.

\section{Results}

From the initial list of 95 tools found in the step one of the research process, four tools meet the two sets of selection criteria applied in steps 2 and 3 (i.e., those based on the nature and usability of the tools themselves and those deemed relevant or desirable by designers). Results from the expert interviews confirmed that the tools most likely to be suitable for urban designers and architects in Oceania are ARIES (Artificial Intelligence for Ecosystem Services), Costing Nature, InVEST (Integrated Valuation of Ecosystem Services and Trade-offs), and LUCI (Land Utilisation and Capability Indicator). The strengths and limitations of these tools are elaborated on in the following sections where the tools are presented by ascending complexity of application. The four tools allow spatially explicit biophysical quantification of ecosystem services in most regions of the world. The type and number of ecosystem services assessed vary among tools and the outputs' reliability tends to depend on the user's technical expertise and commitment. Even though they all assess ecosystem services relevant to the urban environment, none of the four tools were initially designed for application in cities. Examples of their application in the urban Oceania context is thus very limited. LUCI is the most applied tool in the Oceania and Asia-Pacific region, which is not surprising because its development is led from New Zealand [45]. InVEST has been extensively used in the Caribbean and the Asia region possibly because the developers, who are based at Stanford University, USA, are collaborating with the Chinese Academy of Sciences among other international partners [46]. Few case studies of coastal application are available for ARIES and Costing Nature. InVEST and LUCI appear to demonstrate stronger potential in both application to coastal areas and their ability to be easily adapted to consider coastal climate change issues including sea level rise (which both consider). Table 4 presents some of the tools' characteristics, and Table 5 details the ecosystem services assessed by each tool.

Details in Table 4 were derived from the following sources: for ARIES [30,32,47-53]; for Costing Nature [32,54,55]; for InVEST [32,46,49-51,56-60]; and for LUCI [30-32,45,50,61,62].

Table 4. Ecosystem services tool characteristics.

\begin{tabular}{|c|c|c|c|c|c|}
\hline & Characteristic & ARIES & Costing Nature & InVEST & LUCI \\
\hline \multirow{4}{*}{$\begin{array}{l}\text { Application } \\
\text { context }\end{array}$} & Generalisability & Medium $\left({ }^{*}\right.$ High $)$ & High & High & High \\
\hline & Application context & $\mathrm{T}, \mathrm{F}, \mathrm{M}$ & $\mathrm{T}, \mathrm{F}$ & $\mathrm{T}, \mathrm{F}, \mathrm{M}$ & $\mathrm{T}, \mathrm{F}$ \\
\hline & Scalability & Local-Global & Local-National & Local-Global & Site-National \\
\hline & Resolution & $50 \mathrm{~m} \times 50 \mathrm{~m}$ & $100 \mathrm{~m} \times 100 \mathrm{~m}$ & $10 \mathrm{~m} \times 10 \mathrm{~m}$ & $1 \mathrm{~m} \times 1 \mathrm{~m}$ \\
\hline \multirow{4}{*}{ Outputs } & Monetary valuation & $\checkmark$ & $\checkmark$ & $\checkmark$ & \\
\hline & Type of outputs & $\mathrm{A}, \mathrm{R}$ & $\mathrm{R}$ & $\mathrm{A}, \mathrm{R}$ & $\mathrm{A}, \mathrm{R}$ \\
\hline & Trade-offs & $\checkmark$ & & $\checkmark$ & $\checkmark$ \\
\hline & Scenario/Forecast & $\checkmark$ & $\checkmark$ & $\checkmark$ & $\checkmark$ \\
\hline \multirow{4}{*}{ Model } & $\mathrm{N}^{\circ}$ models within tool & 11 & 13 & 18 & 11 \\
\hline & Platform & GIS (Web-based*) & Web-based & GIS & GIS \\
\hline & Model temporality & S, D & S & $S$ & S \\
\hline & Approach to uncertainty & $\checkmark$ & $\checkmark$ & $\checkmark$ & \\
\hline
\end{tabular}

( $\mathrm{T}$ = terrestrial; $\mathrm{F}$ = freshwater; $\mathrm{M}$ = marine; $\mathrm{A}$ = absolute; $\mathrm{R}=$ relative; $\mathrm{S}=$ static single time period; $\mathrm{D}=$ dynamic temporal variation; ${ }^{*}$ refers to ARIES Explorer). 
Table 5. Ecosystem services assessed by the four tools.

\begin{tabular}{|c|c|c|c|c|c|}
\hline \multicolumn{2}{|r|}{ Ecosystem Services Assessed by Tool } & \multirow[t]{2}{*}{ ARIES } & \multirow[t]{2}{*}{ Costing Nature } & \multirow{2}{*}{$\begin{array}{c}\text { InVEST } \\
\checkmark\end{array}$} & \multirow{2}{*}{$\begin{array}{c}\text { LUCI } \\
\checkmark\end{array}$} \\
\hline$S$ & Habitat (quality and provision) & & & & \\
\hline \multirow{10}{*}{$\mathrm{R}$} & Biological control (pest or disease regulation) & & $\checkmark$ & & \\
\hline & Carbon (storage and sequestration) & $\checkmark$ & $\checkmark$ & $\checkmark$ & $\checkmark$ \\
\hline & Climate regulation & & & $\checkmark$ & \\
\hline & Erosion control, landslide risk, soil stabilisation & $\checkmark$ & $\checkmark$ & $\checkmark$ & $\checkmark$ \\
\hline & Flood mitigation & $\checkmark$ & $\checkmark$ & $\checkmark$ & $\checkmark$ \\
\hline & Pollination & $\checkmark$ & $\checkmark$ & $\checkmark$ & \\
\hline & Sediment regulation/delivery & $\checkmark$ & & $\checkmark$ & $\checkmark$ \\
\hline & Urban Cooling & & & $\checkmark$ & \\
\hline & Urban Flood mitigation & & & $\checkmark$ & $\checkmark$ \\
\hline & Water (quality, purification, or nutrient regulation) & $\checkmark$ & & $\checkmark$ & $\checkmark$ \\
\hline \multirow{5}{*}{$\mathrm{P}$} & Agriculture or aquaculture & $\checkmark$ & & $\checkmark$ & $\checkmark$ \\
\hline & Energy/fuel (fuelwood, solar, hydro, wind, wave) & & $\checkmark$ & $\checkmark$ & \\
\hline & Food (harvested wild goods, hunting or fisheries) & $\checkmark$ & $\checkmark$ & $\checkmark$ & \\
\hline & Raw materials (timber, grazing, fibre, minerals) & & $\checkmark$ & $\checkmark$ & \\
\hline & Water (quantity, yield or provision) & $\checkmark$ & $\checkmark$ & $\checkmark$ & $\checkmark$ \\
\hline \multirow{2}{*}{$\mathrm{C}$} & Aesthetic value & $\checkmark$ & $\checkmark$ & $\checkmark$ & \\
\hline & Recreation & $\checkmark$ & $\checkmark$ & $\checkmark$ & \\
\hline
\end{tabular}

( $\mathrm{S}$ = supporting ecosystem services; $\mathrm{R}=$ regulating ecosystem services; $\mathrm{P}=$ provisioning ecosystem services; $\mathrm{C}=$ cultural ecosystem services).

\subsection{Simple Analysis: Costing Nature}

Costing Nature is a web-accessible tool that values "natural capital" and analyses ecosystem services provided by natural environments. It identifies the beneficiaries of these services and evaluates the impact of human interventions in ecosystems [54]. The tool focuses on mapping conservation priority areas and assessing implications of policy scenarios. There is no application in urban contexts reported in the literature but the tool's applications on the coasts of Ecuador and Madagascar suggest that some of the generated outputs are likely to be relevant to the Oceania context $[63,64]$. The tool has been designed for users lacking GIS expertise, with limited time and budget. Indeed, by using the global dataset included in the tool and the default tool parameters, users can assess ecosystem services anywhere in the global terrestrial realm without any extra data input requirements [55]. Therefore, Costing Nature is the tool with the fewest barriers to use. However, limited output reliability and coarse resolution $(100 \mathrm{~m} \times 100 \mathrm{~m})$ impede its application at the smaller urban site scale [32]. As a consequence, the tool has mostly been used at regional or national scales. Moreover, users are restricted by the inability to adapt or customise the tool and have to rely on the default global datasets. The outputs are not absolute values but relative, generating maps where ecosystem services are bundled, with each pixel indicating the ecosystem service with the highest conservation priority.

\subsection{Intermediate Complexity Options: InVEST and LUCI}

\subsubsection{InVEST}

InVEST is a freely accessible suite of models used to quantify, map, and value "goods and services from nature" [60]. The tool's principal applications include ecosystem services mapping, scenario comparison, economic valuation, land and resource management, impact assessment, and policy making [46]. It is the world's most used tool for spatially modelling ecosystem services with applications in over 60 countries $[50,56]$. Therefore, along with very complete training programs, documentation and user support, new users can benefit from the support and experience of a large community of users in different contexts. InVEST is reported to be faster to use than LUCI and ARIES, but is comparable to LUCI when it comes to new site applications where users must put in considerable effort at the beginning of a project to guarantee the quality of the input data [50]. This is 
supported by some case studies reporting that analysis can suffer from out-of-date data, sometimes requiring data review or generation with a predictive model $[65,66]$. InVEST contains 18 models that assess a broad diversity of ecosystem services, with some focusing specifically on coastal and/or urban environments. Indeed, in response to the increasing demand of users for urban ecosystem services assessment, developers released the Urban Cooling and Urban Flood Risk Mitigation models in early 2020 [67]. Two case studies in the Zhoushan archipelago, China, report that the tool resolution $(10 \mathrm{~m} \times 10 \mathrm{~m})$ was appropriate for ecosystem services assessment on small islands and that the results could be used by decision-makers in city management [68,69].

\subsubsection{LUCI}

LUCI is a GIS-based framework that explores land management scenarios to identify locations where changes in land use and management result in improvements in ecosystem services, or where trade-offs between services are present [61]. It is applicable in diverse contexts such as sustainable development, policy making, conservation, and ecological restoration. LUCI has been widely used in the rural context of New Zealand and the United Kingdom, and applied in Australia, the Philippines, Vietnam, Vanuatu, and other Pacific Islands $[45,70]$. As a first step to providing information to guide decision making, the tool emphasises producing transparent and easy to interpret outputs and generates colour-coded maps where green shows good opportunities for changes and red designates areas that should be preserved or restored. There is also significantly more detail available for users to interrogate and analyse "under the hood". It is accessible for public use, is open source, and can be requested through the developer's website. LUCI is the only tool that can simultaneously model a wide range of different spatial scales while respecting smallscale connectivity of habitats throughout, and is unique in that it can compare multiple ecosystem services at once to identify both trade-offs and synergies (win-win scenarios where multiple services might benefit from single spatial interventions) [50]. The tool's fine resolution (usually $5 \mathrm{~m} \times 5 \mathrm{~m}$ ) at local scales generates useful information, even when detailed input data are missing as illustrated by its use in Port Vila, Vanuatu [20]. In that case study, users correlated some input data with New Zealand data based on subjective considered assumptions because data for Vanuatu were not available.

LUCI's application in locations where the tool has never been used is more time consuming (up to several months) but the developer team has presented different options for parameterisation in a case study in the Philippines [71]. The tool does not yet report uncertainty, or consider supporting or cultural ecosystem services, but it is constantly evolving with ongoing research, for example, for urban application in Christchurch, New Zealand [45]. The pilot study for Wellington, Aotearoa New Zealand, conducted during this research supports the conclusion that LUCI is already somewhat relevant to urban design contexts and could be reasonably easily modified to become more so (see Section 3.4).

\subsection{Complex Analysis: ARIES}

ARIES is the most elaborate tool of the four, with modelling techniques such as agentbased modelling and machine learning that reflect the complex dynamic of ecosystem services flows [32,52]. Most tools primarily focus on the processes that bring ecosystem services into existence (supply), but the basis for ecosystem services valuation in ARIES is the quantification of the actual flow of benefit, including the source, sink, and use of ecosystem services. This is a fuller analysis of not just supply, but also demand and bottlenecks in flows between the two. Therefore, it is not surprising that this tool is more time consuming to use, especially for new site applications. Its approach is to develop global, yet customisable ecosystem services models and promote a community-based model development strategy in which data and models are networked, used, and further developed by users over time [72]. The model can be customised and adapted to local contexts, which requires expertise, but training programs are available to help users through this challenging process [47]. Moreover, developers have announced the release 
of the ARIES Explorer web interface, due in 2020/21, which will enable users with less expertise to work with the tool [47]. Based on the results of the literature review, it is problematic to evaluate the potential difficulties that may arise from ARIES' application at local scales on small islands of the Pacific including Aotearoa New Zealand. Indeed, the most relevant application is a regional scale analysis in the coastal urban environment of the Puget Sounds, United States of America [73]. However, a case study in the United Kingdom reports that the probabilistic approach of the tool can cope with data gaps in data scarce regions, which is often the case in Oceania [50].

\subsection{Comparing the Tools and Selection of LUCI}

Figure 5 illustrates characteristics of the four tools as a radar diagram. This was used to understand not just the characteristics of each tool but how effectively they might be applied in the context of urban design in Oceania. Results from Figure 5 enabled the research team to select LUCI as the tool to be used in the pilot design project part of the research. The diagram showed that LUCI did the best or approximately as well as other reviewed tools in four out of five of the selection criteria. LUCI was also the clear candidate for further examination because it was developed in Aotearoa New Zealand and is mostly used in Oceania.

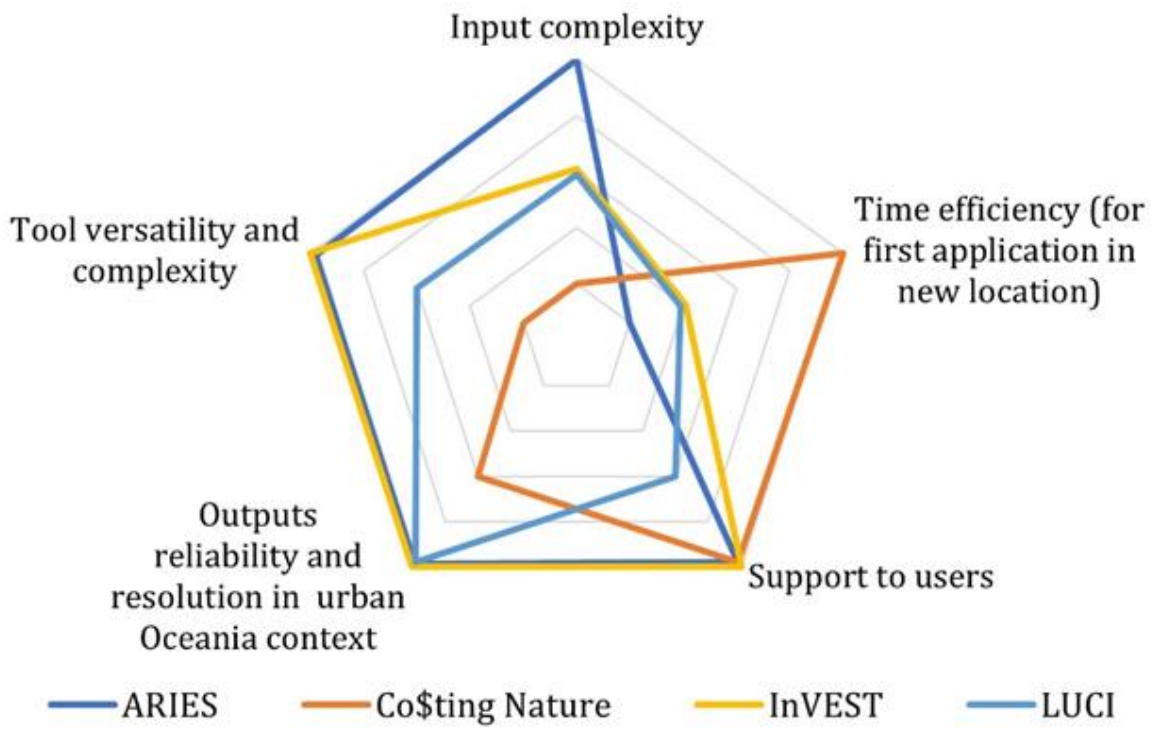

Figure 5. The tools' main technical aspects relevant to the users' selection process.

\subsection{Results of the LUCI Pilot Study in Wellington, Aotearoa New Zealand}

LUCI generates a wide range of maps, tables, and graphics for each tool. In a short period of effort (approximately a month), the analysis generated several $1 \mathrm{~m} \times 1 \mathrm{~m}$ resolution outputs by using readily available national datasets as inputs. The study assessed seven ecosystem services related issues (agricultural productivity, carbon stocks and fluxes, erosion and sediment, flood mitigation, nitrogen, phosphorus, and soil loss) and evaluated the trade-off and synergy interactions between them. This section illustrates some of the maps obtained, presenting the Terrace Gardens results first followed by the Wellington city analysis. The baseline scenario figures illustrate the site condition as processed by LUCI's individual ecosystem services and trade-off tools. Although analysis was performed on all of the ecosystem services available in LUCI, only the flood mitigation outputs are displayed here to illustrate types of results. We have focused on flood mitigation because the hydrology aspect of the results was found to be particularly useful by the design team that was asked to interpret the LUCI results (Section 3.5). LUCI-generated results for other ecosystem services are accessible by contacting the authors. Finally, the combination of the erosion/flooding/nitrogen services illustrates the trade-off outputs. 
The baseline tool generates different layers based on the input provided. The Terrace Gardens site is entirely classified as "urban" for the soil type and "built-up area (settlement)" for the land use (Figure 6A,B). The site has a steep slope going down from west to east as illustrated by the dark grey value of the Hillshade layer (Figure 6C). The three streams start flowing on the downhill side (east) of the Terrace Gardens. Only one of them initiates in the site. These streams were simulated by LUCI through the DEM input data and thus indicate where water would likely flow during high rainfall events, rather than where permanent actual streams exist. The model likely had the capacity to model the Terrace Gardens more accurately with more spatially precise input data, but that required either better mapping of generic data (which is in some cases happening due to improvements in satellites, drones, etc.) or bespoke mapping efforts.

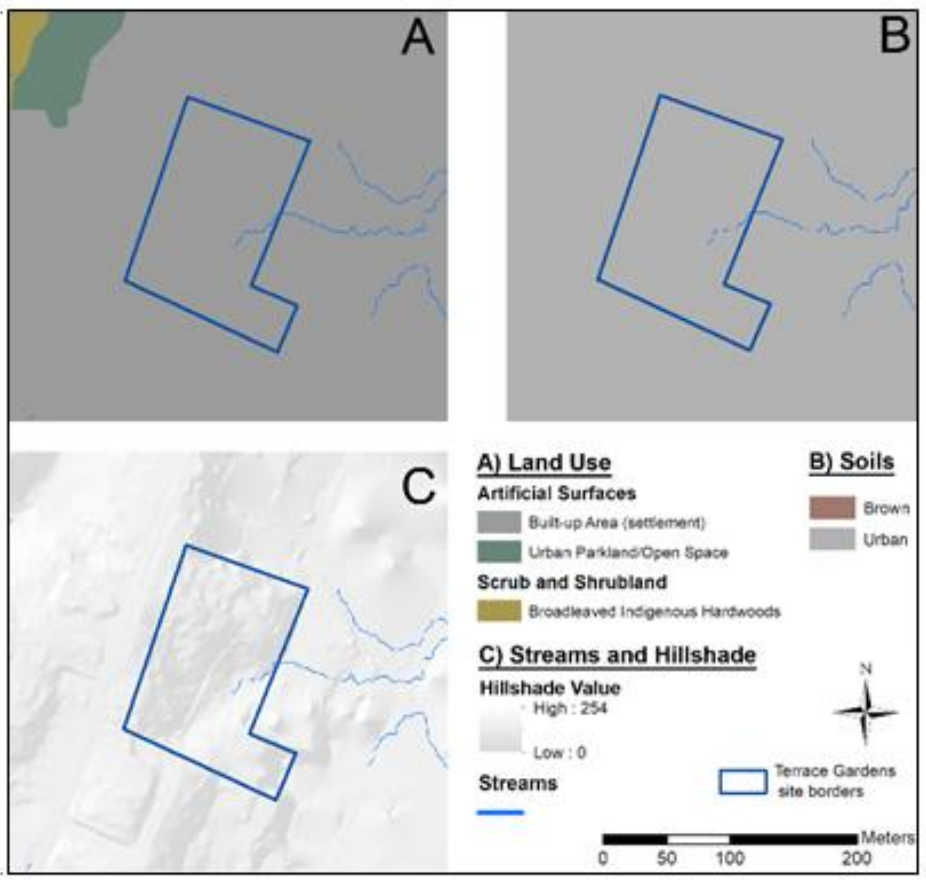

Figure 6. Baseline scenario outputs of the Terrace Gardens.

The LUCI analysis in terms of one individual ecosystem service tool, flood mitigation, reveals that the Terrace Gardens site lacks flood mitigating features (Figure 7B). The flood interception classification (Figure 7A) describes the area (in red and a $1 \mathrm{~m}$ resolution) were water holding capacity and infiltration capacity are low and may be causing high flow concentrations. The flows of water that would occur in heavy rainfall events are low $\left(<1 \mathrm{~m}^{3} / \mathrm{s}\right)$ because the site is the source of them.

Considering the trade-off tool, which was used to examine erosion/flooding/nitrogen, the results suggest that there are opportunities to enhance multiple services in approximately $50 \%$ of the site (Figure 8).

The fine resolution allows identification of a cluster area where significant improvements are possible. The nitrogen service results indicated no current issues with nitrogen on site. Therefore, the trade-off results suggest that the erosion and flood ecosystem services could be enhanced without interfering with the nitrogen ecosystem service. We note, however, the focus on nitrogen as a main contaminant is in part due to LUCI's origins which emphasised enhancing ecosystems in rural agricultural landscapes. Future applications of LUCI to enhance services from urban greenspaces might benefit from consideration of urban contaminants such as zinc, lead, and copper. This capacity has very recently been added to LUCI, after this Wellington analysis had already been completed, as part of the previously mentioned work adapting LUCI to be a better fit for urban contexts in Christchurch, Aotearoa New Zealand. 


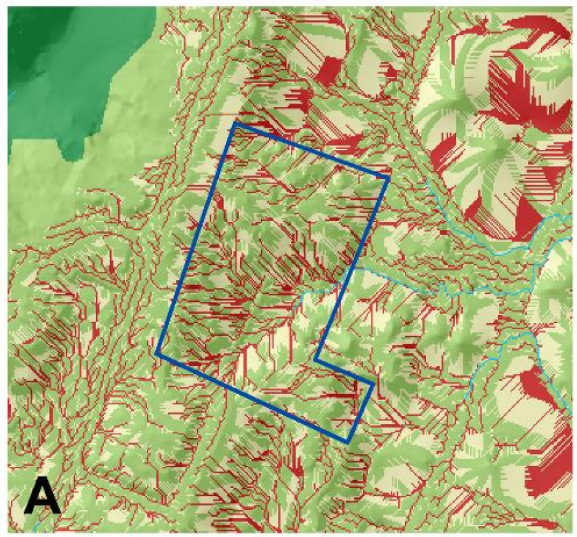

\title{
A) Flood Interception Classification
}

\author{
Flood mitigating land \\ Low flood concentration \\ Moderate flood concentration \\ High flood concentration \\ Water bodies
}

\section{B) Flood Mitigation Classification}

\section{Mitigating features \\ Mitigated features \\ Non-mitigated features \\ Water bodies}

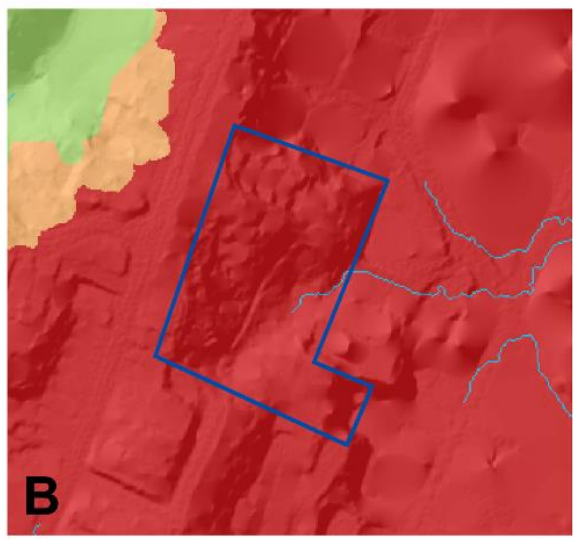

\section{Others}

Average Flow (cumecs average)

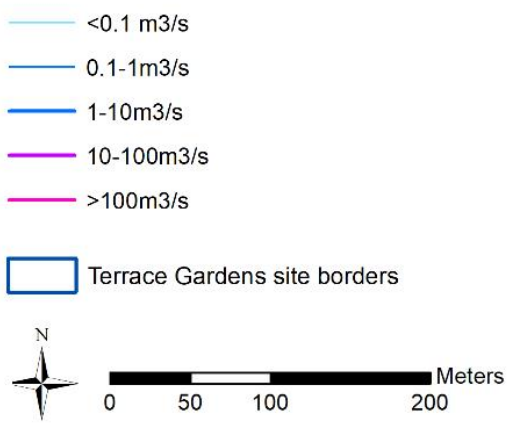

Figure 7. Flood mitigation service outputs on the Terrace Gardens.

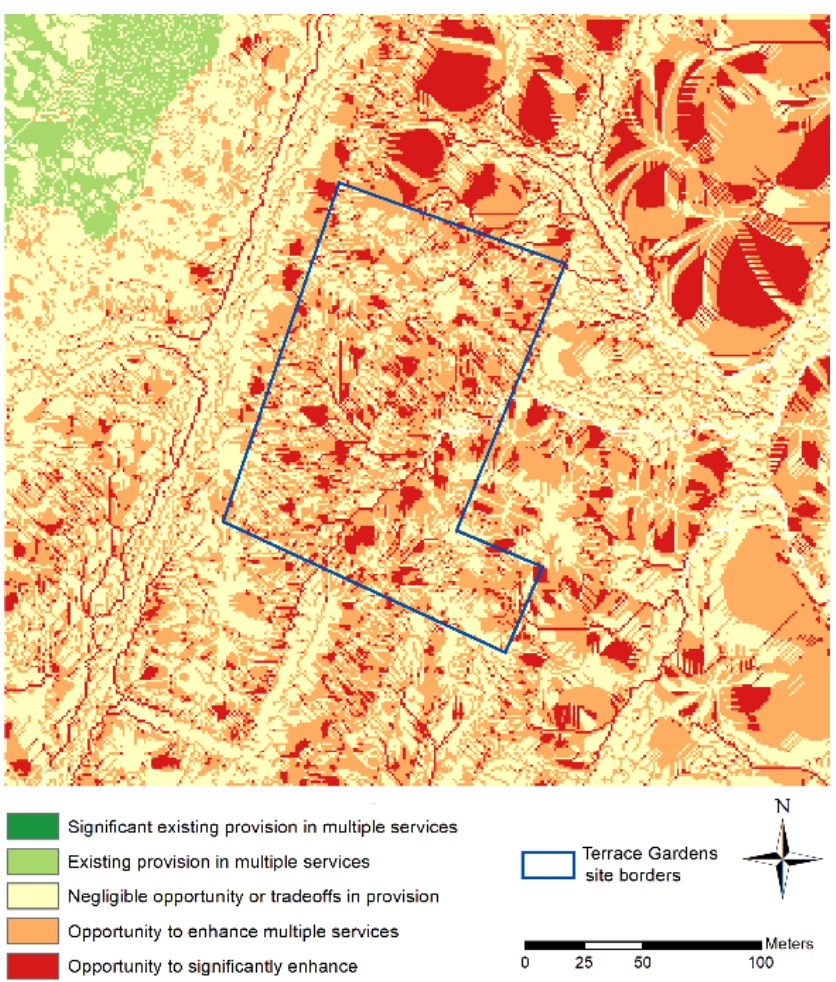

Figure 8. Trade-off between the erosion, flood and nitrogen services in the Terrace Gardens.

When examining results for the larger Wellington CBD analysis, it was found that there are twelve different land types, predominantly, artificial surfaces and scrub. The soils 
layer indicates only two different types, namely, "brown" and "urban". The soil outputs depict a dual environment of the urban centre and urban green areas. There are multiple streams of different flow densities. Only four are flowing through the city centre, but most are below ground (although LUCI does not recognize this). Again, for the larger Wellington analysis, the individual ecosystem service of flood mitigation will be reported on here. Results suggest that $43.49 \%\left(16.24 \mathrm{~km}^{2}\right)$ of the site would benefit from intervention to improve the current flood mitigation situation. The specific areas at risk, shown as red in the flood interception classification, are mainly located in the urban area (referred to as "built-up settlement" land use type). Figure 9 illustrates the outputs generated for flood mitigation ecosystem services (left) in parallel with the city aerial map (right). In this context, mitigating features means land cover/soil types capable of intercepting flow before it reaches water bodies. Mitigated features means areas producing flow that pass through mitigating features before streams, and non-mitigated features indicates areas where the flow from those areas are not intercepted by mitigating features before reaching the streams.

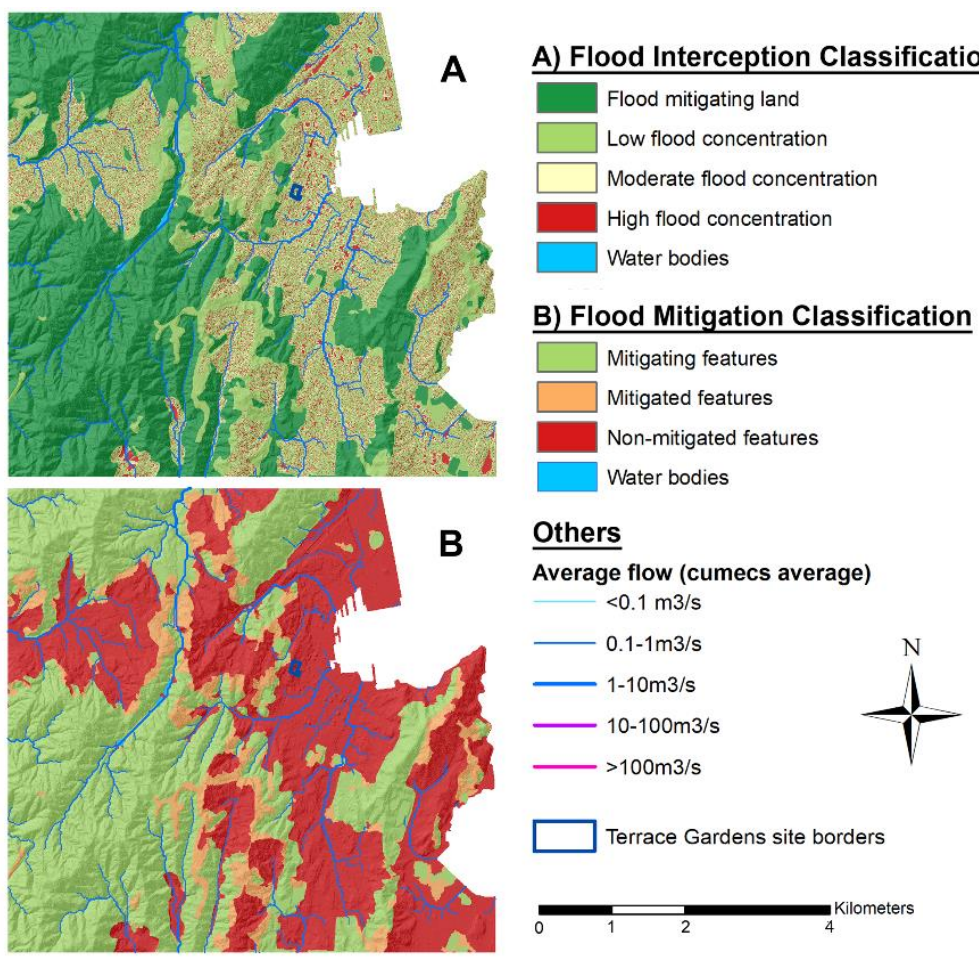

Figure 9. Flood mitigation ecosystem service outputs for Wellington City, Aotearoa New Zealand.

The trade-off tool was used to again analyse relationships between erosion, flooding, and nitrogen. Results indicate that there are opportunities to improve these ecosystem services in $23.50 \%$ of the site (Figure 10). These opportunity areas coincide with the areas that lack flood mitigation features. The nitrogen situation is reported as being relatively good through LUCI; therefore, the trade-off outputs suggest specific areas where interventions could lower the risk of flooding and erosion without negatively affecting the nitrogen ecosystem service. 


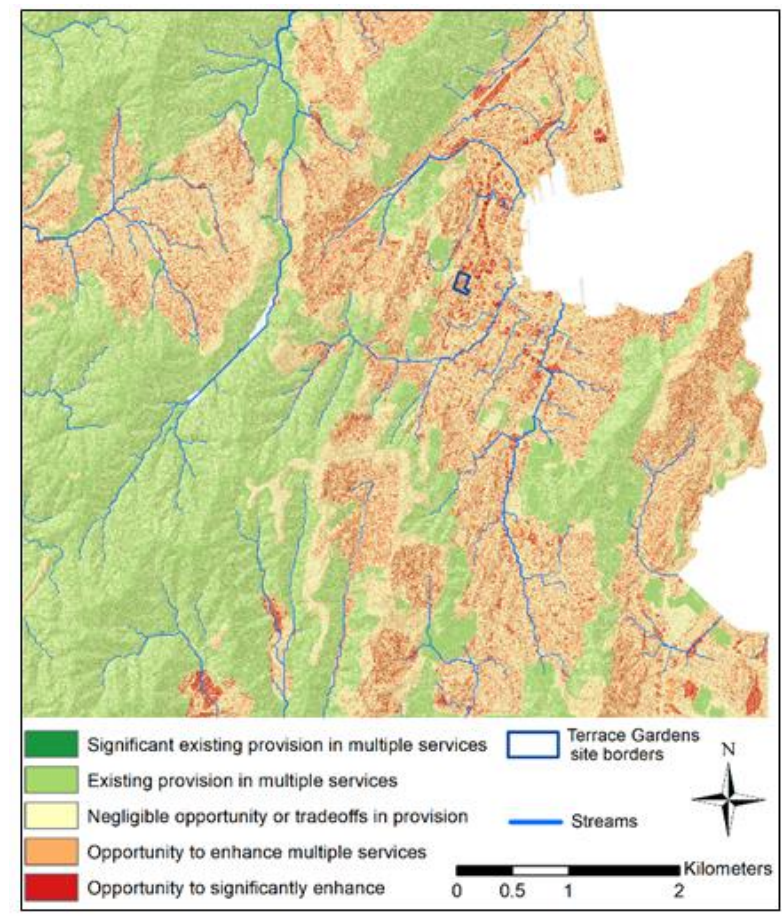

Figure 10. Trade-off between the erosion, flood, and nitrogen services in Wellington City.

Interpreting LUCI Results in a Design Context

The final aspect of the short pilot study using LUCI in Wellington consisted of the results (specifically the maps generated by LUCI) being integrated into a Master of Architecture (Professional) project by a student architect/urban designer at the Wellington School of Architecture at Victoria University of Wellington in Aotearoa New Zealand. This was performed to ascertain how the architect/urban designer interpreted and then used the LUCI results and how this might influence or change design thinking and practice. This was determined by conducting a series of in depth semi-structured interviews with the designer at various stages of the design project. Because this was a single design project, the results should be interpreted cautiously. Despite this, useful observations were made regarding how using LUCI contributed to the urban design process in this instance. This information was then fed back to LUCI developers.

While designers are generally adept at using computer aided design and GIS to obtain land and water information, it was found that the information provided by LUCI was different and highlighted more detailed hydrological information than what was typically used in design contexts. Its integration in the early stages of a project led to new design thinking that helped to shape the design. Specifically, it was found that LUCI provided good insight into master planning on the macro scale both in terms of ecosystem services assessment and hydrological information. This helped the designer to understand which ecosystem services required special attention and specifically where within the urban areas of Wellington interventions should occur.

A second important observation was that the ecosystem services outputs were not all equally relevant to the designer because of the location and focus of the project. For instance, the flood mitigation service intuitively suggested where permeable surfaces were required. The soil erosion ecosystem service outputs showed specific locations where planting of native flora would be beneficial, and the carbon results highlighted areas where plants sequestering carbon should be protected. It was more difficult for the designer to integrate the nitrogen, phosphorous, and agriculture ecosystem services results without consulting an ecology expert because these are more specific to an agricultural context (which LUCI was initially designed for). 
The feedback from the designer highlighted some elements absent in LUCI that would benefit urban applications. For instance, modelling the surface water run-off on impervious surfaces and the existing underground pipes network would bridge the city infrastructure with the natural streams currently considered by LUCI. Furthermore, after further designled research it became evident that certain pollutants are prevalent within the Wellington urban context, such as certain heavy metals $[74,75]$ that were not represented within LUCI. This was thought to be a possible avenue of future development for the tool (with a focus on "purification" ecosystem services for example) to make it even more useful in an urban context as discussed in Section 3.4. The collaboration and findings from this part of the research also suggested that building locations and functions, areas of pond/lagoon formation, and descriptions/locations of particulates and pollution run-off are additional outputs that would be useful in furthering urban applications of LUCI (and likely other ecosystem services tools also).

\section{Discussion}

This section first considers results related to the initial review of ecosystem services assessment tools and then moves into discussion of the pilot study research.

\subsection{Understanding and Applying Ecosystem Services Assements Tools for Use in Oceania}

It is beyond the scope of this article to provide a detailed evaluation of all existing ecosystem services assessment tools and their usefulness/value for the specific context of Oceania. This review does provide however a snapshot of the constantly evolving area of ecosystem services assessment tools. Such tools are under continuous development to provide better results, add new functionalities, and facilitate application. Therefore, although this research clearly identifies four tools with likely greater applicability to the Oceania context (ARIES, Urban InVEST, LUCI, and Costing Nature), review of the effectiveness of new or developing tools should be undertaken regularly. Even the four identified tools themselves are under constant development. To summarise: ARIES has announced the release of a Web-based platform (ARIES Explorer due 2021) that will allow users with less expertise to use the tool for example [47]. InVEST has expressed their intention of focusing on urban applications and has recently released two new models: "Urban Cooling" and "Urban Flood Risk Mitigation", as part of the Urban InVEST platform [67]. LUCI developers are involved in a variety of projects. Most important from an urban perspective is the current testing of the tool in Christchurch, Aotearoa New Zealand, with an aim to further develop the LUCI model by taking into account urban infrastructure and representing urban-specific processes such as evaporative cooling [45]. Nothing has been expressed by Costing Nature concerning any development related to the urban context.

The evaluation of ecosystem services tools reveals that urban designers and architects must consider several factors when choosing a tool. Firstly, a critical aspect to consider is the tool's complexity, which correlates to different time commitments for learning the tool and then being able to apply it. Every tool presented is accessible to urban designers, but their suitability will vary depending on the project scale in question. Small individual projects would benefit from easy-to-use and rapidly deployable tools such as Costing Nature, whereas extensive projects conducted over at least several months with collaborators and enough funds are suitable for ARIES.

Secondly, applying the tool in a new context or in a data scarce region often requires supplementary time and effort from users to parametrise or collect data. Tools with global datasets or default inputs such as Costing Nature might be advantageous in this case, bearing in mind that outputs will be less accurate. Users should search for previous case studies in their context, which sometimes describes parametrisation methods used. ARIES has a library of models previously developed by users, therefore once the tool has been applied somewhere, that particular model can be further adapted for new projects. Indeed, the second application with tools such as ARIES, LUCI, and InVEST is much less time 
consuming because the input data collection and model parametrisation do not have to be repeated.

Thirdly, time availability also impacts the quality of the results. Unsurprisingly, the quality of the outputs is inversely correlated to the time invested in the tool application. Outputs that are rapidly generated based on global datasets are not as reliable and accurate as outputs generated by complex analysis based on users' site-specific inputs and locally attuned parametrisation of the model.

Finally, users should consider the type and number of ecosystem services assessed by the tools. For instance, the four tools discussed here have a limited focus on supporting and cultural ecosystem services. Therefore, when time and resources are available, users may consider applying multiple tools in parallel.

\subsection{Insights from the LUCI Pilot Study in Wellington City}

The output comparisons of the baseline, individual services, and trade-off tools between the Terrace Gardens and the Wellington city analyses indicates that the outputs generated on the Terrace Gardens area are identical. The only difference between the two analyses is the presence of streams on the Terrace Gardens in the baseline scenario outputs. No streams were represented in the Terrace Gardens area through the national river dataset, whereas three streams were generated using the high-resolution local DEM within the Terrace Gardens boundaries. It is possible that the high-resolution DEM picked up thresholds of convergence for stream generation at finer spatial scales. This difference is caused by the absence of streams on the site in the national-scale River Environment Classification input data which required a DEM-based simulation to generate streams in the Terrace Gardens analysis. An important difference between the two analyses process is that the RUSLE tool could not estimate soil loss in the Terrace Gardens analysis because the soil data in the whole area were classified as "town", which LUCI assumes is a built-up area that has no risk of soil loss. Overall, these two observations suggest that zooming in on a specific area within a large-scale analysis would be more reliable than only performing the site analysis. Indeed, the tool functionalities would be more effective, and designers would benefit from a systemic lens when taking into consideration a site's surrounding ecological context. This suggests that architects and urban designers should consider and analyse the whole urban context in terms of ecology, rather than focusing solely on site boundary lines, which is typically the case.

A field analysis of the Terrace Gardens was conducted to evaluate LUCI outputs. The baseline outputs indicate that the land use and soil input data, respectively, classify the entire site as "built-up area (settlement)" and "urban". However, the site visit reveals that approximately a third of the surface is impervious walkway and private houses, a third is urban parkland (open space), and a third is dense vegetation and trees. The inaccuracy of the input data is likely to bias the outputs of the individual ecosystem services and trade-off tools within LUCI. For instance, the flood mitigation outputs classify the Terrace Gardens as mostly made up of "non-mitigated features", whereas LUCI usually classifies pervious surfaces and vegetation as "mitigating features". The analysis with the updated local land use input data obtained through the field work generated different ecosystem services outputs which demonstrates that the quality of LUCI outputs can be improved by user customisation of the input data based on field analysis. It illustrates the issue of national/regional datasets missing small-scale features that may be crucial for specific ecosystem services. For a small site such as the Terrace Gardens, this would probably take a couple of days. However, this requires ecological knowledge that is not common among designers and again points to the need for early collaboration between ecology experts and designers.

As discussed, it is not common for urban designers to access the type of information provided by LUCI, but the possibility to simulate future scenarios with LUCI is sparking interest because traditional tools and methods used by urban designers to collect hydrological and ecological data often only provide static information for a given location at a 
specific time. It was found that use of ecosystem services tools by designers can facilitate collaboration with environmental experts in later stages of the design. The discussion certainly supported the notion that regenerative urban design projects can benefit from the use of ecosystem services assessment tools and demonstrated that spatially explicit ecosystem services tools are useful for regenerative urban design projects because of their ability to locate and highlight "hotspots" where interventions need to be made to improve ecosystem services.

\section{Conclusions}

This research reviewed a wide range of ecosystem service assessment tools to identify those that might be suitable for designers of the built environment to apply in cities of Oceania. It identified four ecosystem services assessment tools as being particularly promising, namely, ARIES, Costing Nature, InVEST, and LUCI. These four modelling tools allow spatially explicit visualisation of the biophysical quantification of ecosystem services and can facilitate the inclusion of ecosystem services considerations into sustainable and regenerative urban design processes. The ecosystem services assessed vary among tools, and the outputs' reliability depends on the user's technical expertise and the history of previous application on or near the site. Results inform future users about crucial characteristics such as time, outputs quality, user commitment, and resource availability in order to choose the tool that best suits their design project requirements. Overall, the tools can be ordered by complexity of application: Costing Nature allows rapid and simple analysis, InVEST and LUCI offer intermediate options, and ARIES is the most difficult to apply. The tools' ongoing development and the interest in the urban context by LUCI and InVEST developers in particular illustrate that tool functionality, generalisability, and ease of application for architects and urban designers are likely to improve in the future.

The LUCI pilot study in Wellington supports the findings from the literature review and illustrates the "complexity" classification used to compare the tools. LUCI is relevant for urban application and can lead to a new design thinking when applied by designers of the built environment. Moreover, the study illustrates that LUCI outputs provide material that can facilitate collaboration between ecology experts and designers when ecosystem services principles are integrated early in the design process.

This research focused on Oceania; however, implications for application of these tools in other cities of the world should not be negated. This comparative research is limited to a literature review because the four tools have never been applied at the same location in an urban context. Future research should thus be conducted to evaluate the strengths and weaknesses of the four tools in practice at the same site across different scales. For instance, pilot studies of ARIES, Costing Nature, and InVEST on the Terrace Gardens would provide new insight on the tools' relevance in cities that are comparable to Wellington.

To conclude, integrating ecosystem services tools into EbA and regenerative urban design is promising and should be investigated further by design teams. This is because the need to integrate quantifiable ecology metrics into urban design practices is essential to develop adaptation and mitigation strategies to address environmental and societal challenges.

Author Contributions: Conceptualisation, F.D. and M.P.Z.; methodology, F.D.; software, F.D., R.B. and T.W.; formal analysis, F.D.; investigation, F.D.; data curation, F.D.; writing - original draft preparation, F.D. and M.P.Z.; writing-review and editing, M.P.Z., R.B., B.J., F.D. and T.W.; supervision, M.P.Z. All authors have read and agreed to the published version of the manuscript.

Funding: This research received no external funding.

Institutional Review Board Statement: Not applicable.

Informed Consent Statement: Not applicable.

Data Availability Statement: Not applicable.

Conflicts of Interest: The authors declare no conflict of interest. 


\section{References}

1. Röckstrom, J.; Steffen, W.; Noone, K.; Persson, Å.; Chapin, F.S., III; Lambin, E.F.; Lenton, T.M.; Scheffer, M.; Folke, C.; Schellnhuber, H.J.; et al. A safe operating space for humanity. Nature 2009, 461, 472-475. [CrossRef] [PubMed]

2. Wilby, R.L.; Perry, G.L.W. Climate change, biodiversity and the urban environment: A critical review based on London, UK. Prog. Phys. Geogr. 2006, 30, 73-98. [CrossRef]

3. Yeang, K. Ecological Design as the Biointegration of a Set of 'Infrastructures': The 'Quatrobrid' Constructed Ecosystem. In Ecologies Design: Transforming Architecture, Landscape, and Urbanism; Pedersen Zari, M., Connolly, P., Southcombe, M., Eds.; Routledge: Oxon, UK, 2020; pp. 44-48.

4. Pedersen Zari, M. Mimicking ecosystems for bio-inspired regenerative built environments. J. Intell. Build. Int. $2016,8,57-77$.

5. United Nations Economic and Social Commission for Asia and the Pacific (ESCAP). Ocean Cities Regional Policy Guide; UNESCAP: Bangkok, Thailand, 2019.

6. Bazaz, A.; Bertoldi, P.; Buckeridge, M.; Cartwright, A.; de Coninck, H.; Engelbrecht, F.; Jacob, D.; Hourcade, J.C.; Klaus, I.; Kleijne, K. Summary for Urban Policymakers; IHHS Indian Institute for Human Settlements: Bengaluru, India, 2018. [CrossRef]

7. Van den Bosch, M.; Ode Sang, Å. Urban natural environments as nature-based solutions for improved public health-A systematic review of reviews. Environ. Res. 2017, 158, 373-384. [CrossRef] [PubMed]

8. Hartig, T.; Mitchell, R.; de Vries, S.; Frumkin, H. Nature and health. Annu. Rev. Public Health 2014, 35, 207-228. [CrossRef]

9. Walsh, K.J.E.; McInnes, K.L.; McBride, J.L. Climate change impacts on tropical cyclones and extreme sea levels in the South Pacific-A regional assessment. Glob. Planet. Chang. 2012, 80, 149-164. [CrossRef]

10. Pedersen Zari, M. Regenerative Urban Design and Ecosystem Biomimicry; Routledge: Oxon, UK, 2018.

11. Mang, P.; Haggard, B. Regenerative Development and Design: A Framework for Evolving Sustainability; John Wiley \& Sons: New York, NY, USA, 2016.

12. Cohen-Shacham, E.; Walters, G.; Janzen, C.; Maginnis, S. Nature-Based Solutions to Address Global Societal Challenges; IUCN: Gland, Switzerland, 2016.

13. Pedersen Zari, M.; Kiddle, G.L.; Blaschke, P.; Gawler, S.; Loubser, D. Utilising nature-based solutions to increase resilience in Pacific Ocean Cities. Ecosyst. Serv. 2019, 38, 1-10. [CrossRef]

14. Colls, A.; Ash, N.; Ikkala, N. Ecosystem-Based Adaptation: A Natural Response to Climate Change; IUCN: Gland, Switzerland, 2009.

15. Costanza, R.; D’Arge, R.; de Groot, R.; Farber, S.; Grasso, M.; Hannon, B.; Limburg, K.; Naeem, S.; O’Neill, R.V.; Paruelo, J.; et al The Value of the World's Ecosystem Services and Natural Capital. Nature 1997, 387, 253-260. [CrossRef]

16. Millennium Ecosystem Assessment. Ecosystems and Human Well-Being: Current State and Trends; Island Press: Washington, DC, USA, 2005; Volume 1.

17. Carpenter, S.R.; Mooney, H.A.; Agard, J.; Capistrano, D.; DeFries, R.S.; Diaz, S.; Dietz, T.; Duraiappah, A.K.; Oteng-Yeboah, A.; Pereira, H.M.; et al. Science for managing ecosystem services: Beyond the Millennium Ecosystem Assessment. Proc. Natl. Acad. Sci. USA 2009, 106, 1305-1312. [CrossRef]

18. Świątek, L. Regenerative Ergonomic Design-Biocentric Evolution. In Advances in Human Factors, Sustainable Urban Planning and Infrastructure, Advances in Intelligent Systems and Computing; Charytonowicz, J., Ed.; Springer International Publishing: Cham, Switzerland, 2018; pp. 96-105. [CrossRef]

19. Reed, B.; Haggard, B. Engaging with life: The developmental practice of regenerative development and design. In Ecologies Design: Transforming Architecture, Landscape, and Urbanism; Pedersen Zari, M., Connolly, P., Southcombe, M., Eds.; Routledge: Oxon, UK, 2020.

20. Pedersen Zari, M.; Blaschke, P.M.; Jackson, B.; Komugabe-Dixson, A.; Livesey, C.; Loubser, D.I.; Martinez-Almoyna Gual, C.; Maxwell, D.; Rastandeh, A.; Renwick, J.; et al. Devising urban Ecosystem-based Adaptation (EbA) projects with developing nations: A case study of Port Vila, Vanuatu. Ocean Coast. Manag. 2019, 184, 1-14. [CrossRef]

21. IPCC. Summary for Policymakers. In Global Warming of $1.5^{\circ} \mathrm{C}$. An IPCC Special Report on the Impacts of Global Warming of $1.5^{\circ} \mathrm{C}$ above Pre-Industrial Levels and Related Global Greenhouse Gas Emission Pathways, in the Context of Strengthening the Global Response to the Threat of Climate Change, Sustainable Development, and Efforts to Eradicate Poverty; IPCC Press: Geneva, Switzerland, 2018.

22. Nurse, L.; Sem, G.; Hay, J.; Suarez, A.; Wong, P.; Briguglio, L.; Ragoonaden, S. Small Island States. In Climate Change 2001: Impacts, Adaptation, and Vulnerability: Contribution of Working Group II to the Third Assessment Report of the Intergovernmental Panel on Climate Change; Cambridge University Press: Cambridge, UK, 2001; pp. 845-870.

23. Ausseil, A.G.E.; Daigneault, A.J.; Frame, B.; Teixeira, E.I. Towards an integrated assessment of climate and socio-economic change impacts and implications in New Zealand. Environ. Model. Softw. 2019, 119, 1-20. [CrossRef]

24. Blaschke, P.; Chapman, R.; Gyde, E.; Howden-Chapman, P.; Ombler, J.; Pedersen Zari, M.; Perry, M.; Randal, E. Green Space in Wellington's Central City: Current Provision, and Design for Future Wellbeing; Wellington City Council: Wellington, UK, 2019.

25. Wellington City Council. Our City Tomorrow: Planning for Growth [WWW Document]. Wellington City Council, 2019. Available online: https:/ / planningforgrowth.wellington.govt.nz/ (accessed on 7 July 2020).

26. Komugabe-Dixson, A.F.; de Ville, N.S.E.; Trundle, A.; McEvoy, D. Environmental change, urbanisation, and socio-ecological resilience in the Pacific: Community narratives from Port Vila, Vanuatu. Ecosyst. Serv. 2019, 39, 1-13. [CrossRef]

27. Balzan, M.V.; Potschin-Young, M.; Haines-Young, R. Island ecosystem services: Insights from a literature review on case-study island ecosystem services and future prospects. Int. J. Biodivers. Sci. Ecosyst. Serv. Manag. 2018, 14, 71-90. [CrossRef] 
28. Rosenthal, A.; Verutes, G.; McKenzie, E.; Arkema, K.K.; Bhagabati, N.; Bremer, L.L.; Olwero, N.; Vogl, A.L. Process matters: A framework for conducting decision-relevant assessments of ecosystem services. Int. J. Biodivers. Sci. Ecosyst. Serv. Manag. 2014, 11, 190-204. [CrossRef]

29. Burkhard, B.; Maes, J. Mapping ecosystem services. Adv. Books 2017, 1, e12837.

30. Bagstad, K.J.; Semmens, D.J.; Waage, S.; Winthrop, R. A comparative assessment of decision-support tools for ecosystem services quantification and valuation. Ecosyst. Serv. 2013, 5, 27-39. [CrossRef]

31. Grêt-Regamey, A.; Sirén, E.; Brunner, S.H.; Weibel, B. Review of decision support tools to operationalize the ecosystem services concept. Ecosyst. Serv. 2017, 26, 306-315. [CrossRef]

32. Neugarten, R.A.; Langhammer, P.F.; Osipova, E.; Bagstad, K.J.; Bhagabati, N.; Butchart, S.H.M.; Dudley, N.; Elliott, V.; Gerber, L.R.; Arrellano, C.G.; et al. Tools for Measuring, Modelling, and Valuing Ecosystem Services; IUCN: Gland, Switzerland, 2018.

33. Hugé, J.; Rochette, A.J.; de Béthune, S.; Parra Paitan, C.C.; Vanderhaegen, K.; Vandervelden, T.; Van Passel, S.; Vanhove, M.P.M.; Verbist, B.; Verheyen, D. Ecosystem services assessment tools for African Biosphere Reserves: A review and user-informed classification. Ecosyst. Serv. 2020, 42, 101079. [CrossRef]

34. Oosterbroek, B.; de Kraker, J.; Huynen, M.M.T.E.; Martens, P. Assessing ecosystem impacts on health: A tool review. Ecosyst. Serv. 2016, 17, 237-254. [CrossRef]

35. Pandeya, B.; Buytaert, W.; Zulkafli, Z.; Karpouzoglou, T.; Mao, F.; Hannah, D.M. A comparative analysis of ecosystem services valuation approaches for application at the local scale and in data scarce regions. Ecosyst. Serv. 2016, 22, 250-259. [CrossRef]

36. Bowman, A. Flagstaff Hill, Percival Street and Terrace Gardens [WWW Document]. Wellington Steps. 2018. Available online: https: / / wellingtonsteps.com/2018/12/06/percival-street-and-terrace-gardens / (accessed on 7 August 2020).

37. Hecht, K. Mapping and Illustrating Design Strategies for Urban Ecosystem Services Generation; Master of Bio-Inspired Design Internship Report; Utrecht University: Utrecht, The Netherlands, 2019.

38. LUCI Team. LUCI Help Documentation. 2019. Available online: https://www.lucitools.org/assets/Uploads/LUCIDocumentation-as-of-April-2019.pdf? (accessed on 4 March 2021).

39. Klik, A.; Haas, K.; Dvorackova, A.; Fuller, I.C. Spatial and temporal distribution of rainfall erosivity in New Zealand. Soil Res. 2015, 53, 815-825. [CrossRef]

40. Land Information New Zealand. Wellington LiDAR 1m DEM. 2013. Available online: https://data.linz.govt.nz/layer/53621wellington-lidar-1m-dem-2013/ (accessed on 7 August 2020).

41. Land Resource Information Systems. New Zealand Land Cover Database Version 5.0. 2020. Available online: https:/ lris.scinfo. org.nz/layer/104400-lcdb-v50-land-cover-database-version-50-mainland-new-zealand/ (accessed on 7 August 2020).

42. Land Resource Information Systems. New Zealand Fundamental Soil Layer. 2010. Available online: https://1ris.scinfo.org.nz/ layer/48136-fsl-north-island-all-attributes / (accessed on 7 August 2020).

43. National Institute of Water and Atmospheric Research Ltd. River Environment Classification Wellington [WWW Document]. 2010. Available online: https:/ / data.mfe.govt.nz/layer/51829-river-environment-classification-wellington-2010/metadata/ (accessed on 7 August 2020).

44. National Institute of Water and Atmospheric Research Ltd. Virtual Climate Station Data and Products. 2018. Available online: https:/ / niwa.co.nz/climate/our-services/virtual-climate-stations (accessed on 7 August 2020).

45. LUCI Home Page. Available online: https://www.lucitools.org/ (accessed on 8 July 2020).

46. Natural Capital Project Who We Are. Available online: https://naturalcapitalproject.stanford.edu/who-we-are/natural-capitalproject (accessed on 7 July 2020).

47. ARIES. ARIES-ARtificial Intelligence for Ecosystem Services. 2020. Available online: http://aries.integratedmodelling.org/ (accessed on 8 July 2020).

48. Bagstad, K.J.; Villa, F.; Johnson, G.W.; Voigt, B. ARIES: A Guide to Models and Data, Version 1.0; The ARIES Consortium, 2011. Available online: https:/ / unstats.un.org/unsd/envaccounting/seeaRev/meeting2013/EG13-BG-7.pdf (accessed on 5 March 2021).

49. Beck, M.W.; Lange, G.M. (Eds.) Managing coasts with natural solutions: Guidelines for measuring and valuing the coastal protection services of mangroves and coral reefs. In Wealth Accounting and the Valuation of Ecosystem Services Partnership (WAVES); World Bank: Washington, DC, USA, 2016.

50. Sharps, K.; Masante, D.; Thomas, A.; Jackson, B.; Redhead, J.; May, L.; Prosser, H.; Cosby, B.; Emmett, B.; Jones, L. Comparing strengths and weaknesses of three ecosystem services modelling tools in a diverse UK river catchment. Sci. Total Environ. 2017, 584, 118-130. [CrossRef]

51. Vigerstol, K.L.; Aukema, J.E. A comparison of tools for modeling freshwater ecosystem services. J. Environ. Manag. 2011, 92, 2403-2409. [CrossRef]

52. Villa, F.; Bagstad, K.J.; Voigt, B.; Johnson, G.W.; Portela, R.; Honzák, M.; Batker, D. A methodology for adaptable and robust ecosystem services assessment. PLoS ONE 2014, 9, e91001. [CrossRef]

53. Villa, F.; Ceroni, M.; Bagstad, K.; Johnson, G.; Krivov, S. ARIES (ARtificial Intelligence for Ecosystem Services): A new tool for ecosystem services assessment, planning, and valuation. In Proceedings of the 11th Annual BIOECON Conference on Economic Instruments to Enhance the Conservation and Sustainable Use of Biodiversity, Venice, Italy, 21-22 September 2009.

54. Mulligan, M. Documentation for the CostingNature Model V3. Available online: www.policysupport.org/costingnature (accessed on 7 July 2020). 
55. Policy Support. Costing Nature. 2020. Available online: http:/ / www.policysupport.org/costingnature (accessed on 7 July 2020).

56. Ochoa, V.; Urbina-Cardona, N. Tools for spatially modeling ecosystem services: Publication trends, conceptual reflections and future challenges. Ecosyst. Serv. 2017, 26, 155-169. [CrossRef]

57. Daily, G.C.; Polasky, S.; Goldstein, J.; Kareiva, P.M.; Mooney, H.A.; Pejchar, L.; Ricketts, T.H.; Salzman, J.; Shallenberger, R. Ecosystem services in decision making: Time to deliver. Front. Ecol. Environ. 2009, 7, 21-28. [CrossRef]

58. Ruckelshaus, M.; McKenzie, E.; Tallis, H.; Guerry, A.; Daily, G.; Kareiva, P.; Polasky, S.; Ricketts, T.; Bhagabati, N.; Wood, S.A.; et al. Notes from the field: Lessons learned from using ecosystem service approaches to inform real-world decisions. Ecol. Econ. 2015, 115, 11-21. [CrossRef]

59. Sharp, R.; Tallis, H.T.; Ricketts, T.; Guerry, A.D.; Wood, S.A.; Chaplin-Kramer, R.; Nelson, E.; Ennaanay, D.; Wolny, S.; Olwero, N.; et al. InVEST 3.6.0 User's Guide, The Natural Capital Project, Stanford University, University of Minnesota, The Nature Conservancy, and World Wildlife Fund. Available online: http:/ / releases.naturalcapitalproject.org/invest-userguide/latest/ (accessed on 8 July 2020).

60. Tallis, H.; Polasky, S. Mapping and valuing ecosystem services as an approach for conservation and natural resource management. Ann. N. Y. Acad. Sci. 2009, 1162, 265-283. [CrossRef] [PubMed]

61. Jackson, B.; Pagella, T.; Sinclair, F.; Orellana, B.; Henshaw, A.; Reynolds, B.; Mcintyre, N.; Wheater, H.; Eycott, A. Polyscape: A GIS mapping framework providing efficient and spatially explicit landscape-scale valuation of multiple ecosystem services. Landsc. Urban Plan. 2013, 112, 74-88. [CrossRef]

62. Nayak, D.R.; Smith, P. Review and Comparison of Models Used for Land Allocation and Nature Valuation; University of Aberdeen: Aberdeen, UK, 2019.

63. Burgess, P.; Qin, S.; Li, X. Mangroves in Ecuador: An Application and Comparison of Ecosystem Service Models; Duke University: Durham, NC, USA, 2015; pp. 12-20.

64. Mulligan, M.; van Soesbergen, A.; Hole, D.G.; Brooks, T.M.; Burke, S.; Hutton, J. Mapping nature's contribution to SDG 6 and implications for other SDGs at policy relevant scales. Remote Sens. Environ. 2020, 239, 111671. [CrossRef]

65. Arkema, K.; Fisher, D.; Wyatt, K. Economic Valuation of Ecosystem Services in Bahamian Marine Protected Areas; Prepared for BREEF by The Natural Capital Project; Stanford University: Stanford, CA, USA, 2017.

66. Sharma, S.K.; Baral, H.; Laumonier, Y.; Okarda, B.; Komarudin, H.; Purnomo, H.; Pacheco, P. An Analysis of Multiple Ecosystem Services under Future Oil Palm Expansion Scenarios in Central and West Kalimantan, Indonesia; Occasional Paper 187; CIFOR: Bogor, Indonesia, 2018.

67. Natural Capital Project, Urban InVEST. Available online: https:/ / naturalcapitalproject.stanford.edu/software/invest-models/ development-urban-invest (accessed on 8 July 2020).

68. Cao, W.; Li, R.; Chi, X.; Chen, N.; Chen, J.; Zhang, H.; Zhang, F. Island urbanization and its ecological consequences: A case study in the Zhoushan Island, East China. Ecol. Indic. 2017, 76, 1-14. [CrossRef]

69. Deng, J.; Lin, Y.; Zhou, M.; Wu, C.; Chen, B.; Xiao, G.; Cai, J. Ecosystem services dynamics response to tremendous reclamation in a coastal island city. Ecosyst. Health Sustain. 2019, 5, 155-168. [CrossRef]

70. Tomscha, S.; Deslippe, J.; de Róiste, M.; Hartley, S.; Jackson, B. Uncovering the ecosystem service legacies of wetland loss using high-resolution models. Ecosphere 2019, 10, e02888. [CrossRef]

71. Benavidez, R.; Jackson, B.; Maxwell, D.; Paringit, E. Improving predictions of the effects of extreme events, land use, and climate change on the hydrology of watersheds in the Philippines. In Proceedings of the International Association of Hydrological Sciences, Bochum, Germany, 18-20 May 2016; Volume 373, pp. 147-151.

72. Martínez-López, J.; Bagstad, K.J.; Balbi, S.; Magrach, A.; Voigt, B.; Athanasiadis, I.; Pascual, M.; Willcock, S.; Villa, F. Towards globally customizable ecosystem service models. Sci. Total Environ. 2019, 650, 2325-2336. [CrossRef] [PubMed]

73. Zank, B.; Bagstad, K.J.; Voigt, B.; Villa, F. Modeling the effects of urban expansion on natural capital stocks and ecosystem service flows: A case study in the Puget Sound, Washington, USA. Landsc. Urban Plan. 2016, 149, 31-42. [CrossRef]

74. Wellington Water. An Integrated Catchment Management Plan (ICMP) Is a Plan for the Sustainable Management of Fresh and Coastal Water and Ecosystems; Wellington City Council: Wellington, NZ, USA, 2015. Available online: https:/ / www.wellingtonwater.co. nz/dmsdocument/114 (accessed on 17 December 2020).

75. Andrade Pérez, A.; Herrera Fernandez BCazzolla Gatti, R. (Eds.) Building Resilience to Climate Change: Ecosystem-Based Adaptation and Lessons FROM the Field; IUCN: Gland, Switzerland, 2010. 